\title{
JAHRESVERZEICHNIS DER
}

\section{AN DEN DEUTSCHEN SCHULANSTALTEN ERSCHIENENEN ABHANDLUNGEN}

\author{
$1916-1929$ \\ VORLÄUFIGE VERÖFFENTLICHUNG: PREUSSEN
}

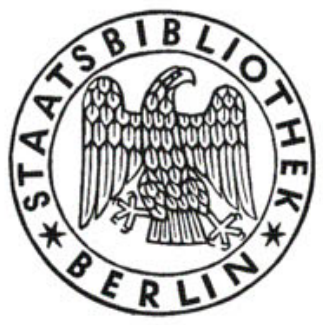

BERLIN UND LEIPZIG

WALTER DE GRUYTER \& CO. 



\title{
JAHRESVERZEICHNIS
}

DER

\section{AN DEN DEUTSCHEN SCHULANSTALTEN ERSCHIENENEN ABHANDLUNGEN}

\author{
$1916-1929$ \\ VORLÄUFIGE VERÖFFENTLICHUNG: PREUSSEN
}

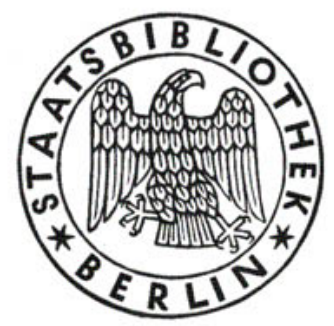

BERLIN UND LEIPZIG

WALTER DE GRUYTER \& CO. 
Druck von August Hopfer, Burg Bz. Magdeburg 


\section{$D_{\text {as Jahres-Verzeichnis der an den Deutschen Schulanstalten }}$}

erschienenen Abhandlungen mußte mit seinem XXVII. Jahrgange (1915) eingestellt werden. Inzwischen sind an den Schulanstalten neuerdings wieder Abhandlungen in genügender Anzahl erschienen, um den Versuch lohnend erscheinen zu lassen, die Lücke für die Zeit von 1916-1929 auszufüllen. Eine Vervollständigung dieser vorläufigen Veröffentlichung, die sich alsdann auf alle deutschen Länder beziehen wird, ist in Vorbereitung.

Berlin, Pfingsten 1930

I. A.:

Lind a $u$ 